\title{
Tunnel-and-bridge strategy for rectal endoscopic submucosal dissection: tips to allow strong countertraction without clip and line
}

Endoscopic submucosal dissection (ESD) is the reference method for curative resection of rectal tumors, reducing the rate of recurrence and allowing complete specimen assessment [1]. Nevertheless, it is technically challenging and new strategies to reduce the procedure time and difficulty, and to improve learning are needed [2-4].

Countertraction, as has been proposed with the clip-and-line technique, allows the submucosal space to be enlarged, making dissection easier [5]. In the rectum, the line creates tangential traction without triangulation.

We present here the tunnel-andbridge strategy ( $\mathbf{F i g . 1}$ and $>$ Fig. 2;

- Video 1). First, the two edges (oral and anal) of the lesion are cut, with incision followed by dissection. A tunnel is then created from the anal to the oral edge. After this step, the two lateral incisions are made without dissection. Finally, the scope is passed through the channel and retroflexion is performed above the oral side, making permanent countertraction for the procedure to be completed by cutting the two lateral submucosal residues with the scope in the retroflexed position. Because of the weight of the scope, a real triangulation is obtained.

This strategy needs to be compared prospectively but seems to offer a good method of countertraction without any additional cost, such as for a clip.

Endoscopy_UCTN_Code_TTT_1AQ_2AD

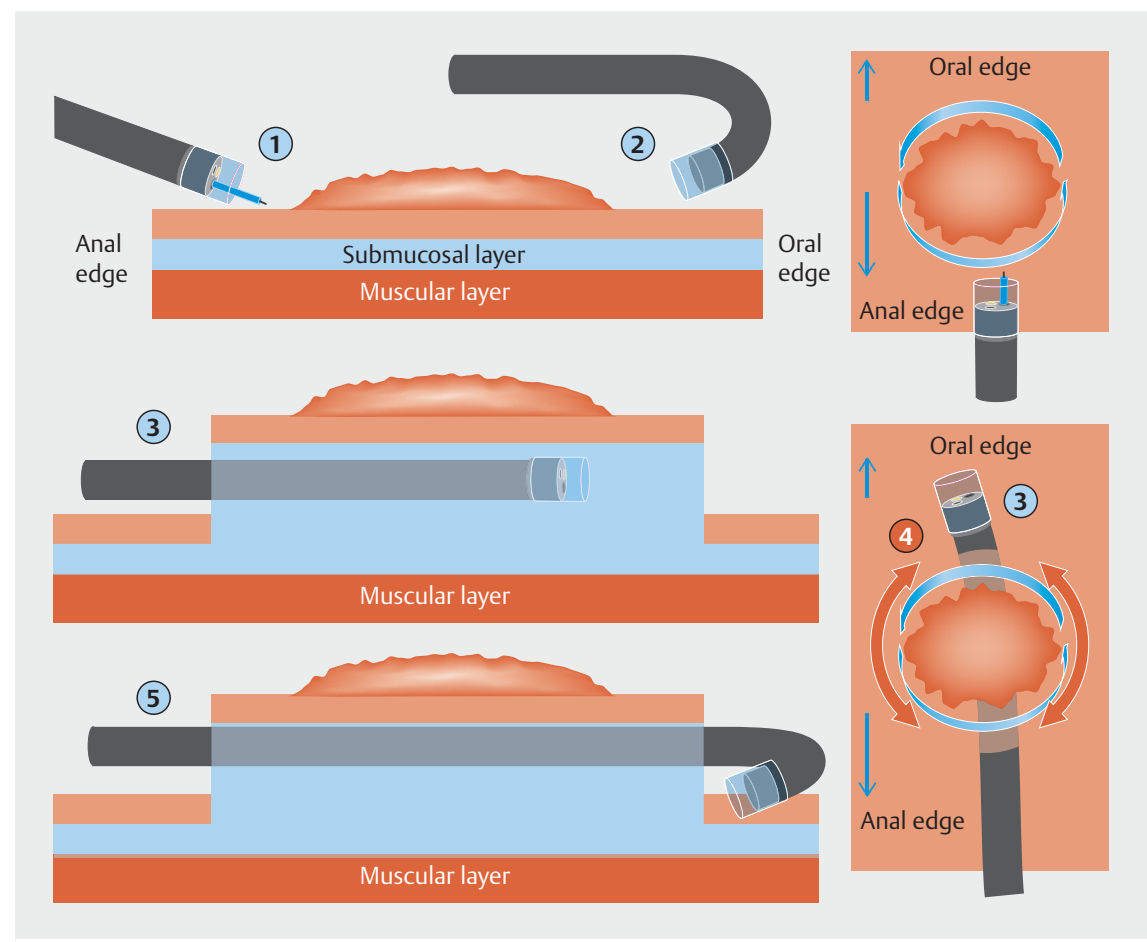

- Fig. 1 Schematic of the tunnel-and-bridge procedure for rectal endoscopic submucosal dissection: (1) an incision is made at the anal side; (2) an incision is made at the oral side with the scope in a retroflexed position; (3) a submucosal tunnel is created under the lesion; (4) the lateral incisions are made; (5) a bridge is created with the scope being retroflexed after being passed through the tunnel.

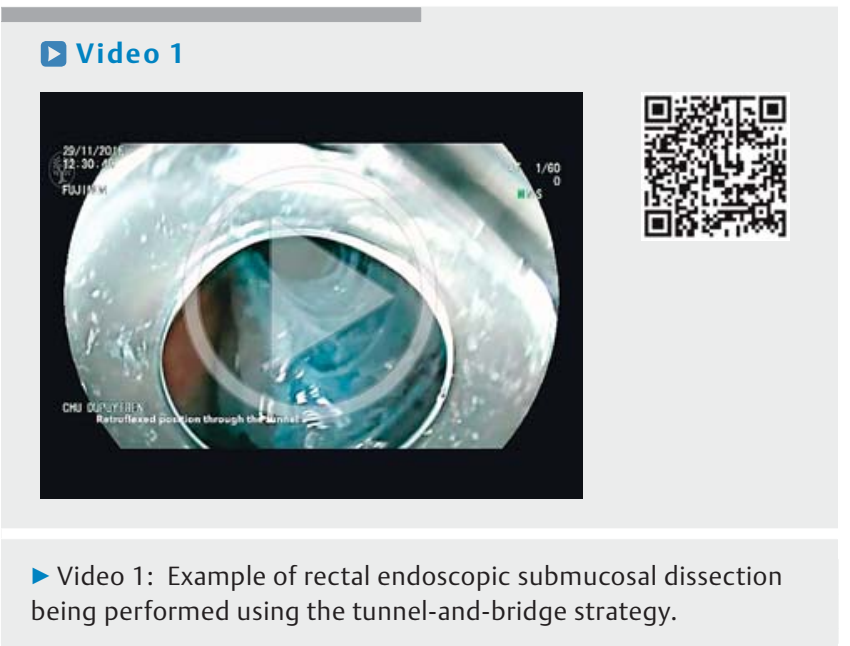




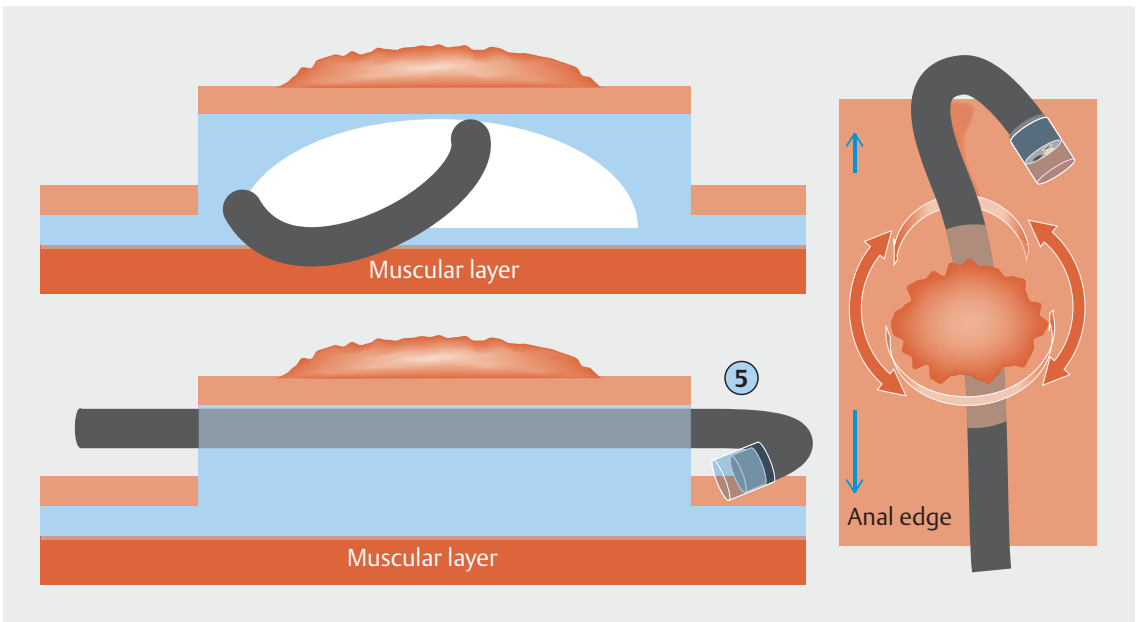

Fig. 2 Further views of the tunnel and bridge created by retroflexion of the scope.

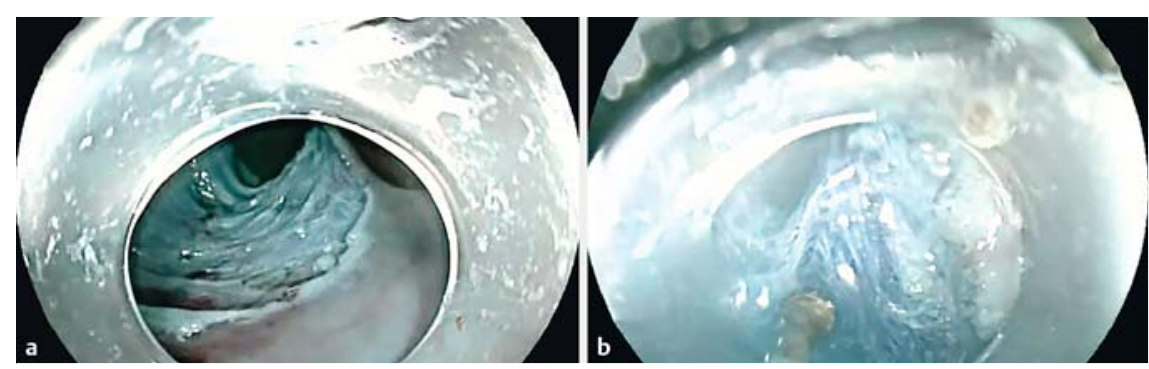

- Fig. 3 Endoscopic views showing: a the bridge effect viewed from the retroflexed position; b dissection of the lateral edge being performed with the scope in the retroflexed position and stretching of the tunnel.
Corresponding author

\section{Mathieu Pioche, MD}

Endoscopy unit - Digestive Disease

Department, H Pavillon - Edouard Herriot

Hospital, 69437 Lyon, France

Fax: +33-4-72110147

mathieu.pioche@chu-lyon.fr

\section{References}

[1] Saito Y, Uraoka T, Yamaguchi Y et al. A prospective, multicenter study of 1111 colorectal endoscopic submucosal dissections (with video). Gastrointest Endosc 2010; 72 : $1217-1225$

[2] Pioche M, Mais L, Guillaud O et al. Endoscopic submucosal tunnel dissection for large esophageal neoplastic lesions. Endoscopy 2013; 45: 1032-1034

[3] Pioche M, Ciocirlan M, Lépilliez V et al. Highpressure jet injection of viscous solutions for endoscopic submucosal dissection: a study on ex vivo pig stomachs. Surg Endosc 2014; 28: $1742-1747$

[4] Pioche M, Rivory J, Nishizawa T et al. Randomized comparative evaluation of an ESD self-learning software in France and Japan. Endoscopy 2016; 48: 1076 - 1083

[5] Jacques ], Geyl S, Carrier P et al. A combination of the clip-with-line method and the tunnel technique during esophageal endoscopic submucosal dissection: a technical solution? Endoscopy 2015; 47 (Suppl. 01): E307-E308

\section{Bibliography}

DOI http://dx.doi.org/10.1055/s-0043-100757

Endoscopy 2017; 49: E123-E124

(c) Georg Thieme Verlag KG

Stuttgart · New York

ISSN 0013-726X research, Boston Scientific: advisory board member, lecture and clinical research, Cook Medical: advisory board member and clinical research, Fujifilm: lecture and clinical research, Medtronics: advisory board member, lecture and clinical research, Ipsen pharma: advisory board member, lecture and clinical research, Ferring: lecture, Nestis: shareholder.
Mathieu Pioche ${ }^{1,2}$, Jérôme Rivory ${ }^{1}$, Vincent Lépilliez $^{3}$, Jean-Christophe Saurin ${ }^{1}$, Thierry Ponchon $^{1,2}$, Jérémie Jacques ${ }^{4}$

1 Gastroenterology and Endoscopy Unit, Edouard Herriot Hospital, Lyon, France 2 Inserm U1032, Labtau, Lyon, France

3 Gastroenterology and Endoscopy Unit, Private Hospital Jean Mermoz, Lyon, France

4 Gastroenterology and Endoscopy Unit, Dupuytren University Hospital, Limoges, France 